University of New Hampshire

University of New Hampshire Scholars' Repository

$7-5-2010$

\title{
Developing brokered community transportation for seniors and people with disabilities
}

\author{
Jerry D. Marx \\ University of New Hampshire, Jerry.Marx@unh.edu \\ Christie Davis \\ University of New Hampshire \\ Caitlyn Miftari \\ University of New Hampshire \\ Anne Salamone \\ University of New Hampshire \\ Wendy Weise \\ University of New Hampshire
}

Follow this and additional works at: https://scholars.unh.edu/socwork_facpub

Part of the Social Work Commons

\section{Recommended Citation}

Marx, J.D., Davis, C., Miftari, C., Salamone, A. \& Weise, W. (2010). Developing brokered community transportation for seniors and people with disabilities. The Journal of Gerontological Social Work, 53(5), 449-466.

This Article is brought to you for free and open access by the Social Work at University of New Hampshire Scholars' Repository. It has been accepted for inclusion in Social Work Scholarship by an authorized administrator of University of New Hampshire Scholars' Repository. For more information, please contact Scholarly.Communication@unh.edu. 
This article was downloaded by: [University of New Hampshire]

On: 27 August 2012, At: 06: 19

Publisher: Routledge

Informa Ltd Registered in England and Wales Registered Number: 1072954 Registered office: Mortimer House, 37-41 Mortimer Street, London W1T 3J H, UK

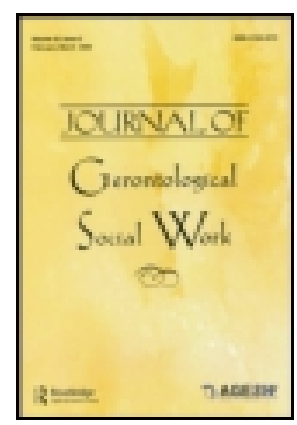

\title{
J ournal of Gerontological Social Work
}

Publication details, including instructions for authors and subscription information:

http:// www.tandfonline.com/loi/ wger20

\section{Developing Brokered Community Transportation for Seniors and People With Disabilities}

\author{
Jerry Marx ${ }^{a}{ }$ Christie Davis $^{a}$, Caitlin Miftari ${ }^{a}$, Anne Salamone ${ }^{a} \&$ \\ Wendy Weise ${ }^{a}$ \\ a Department of Social Work, University of New Hampshire, Durham, \\ New Hampshire, USA
}

Version of record first published: 05 J ul 2010

To cite this article: J erry Marx, Christie Davis, Caitlin Miftari, Anne Salamone \& Wendy Weise (2010): Developing Brokered Community Transportation for Seniors and People With Disabilities, J ournal of Gerontological Social Work, 53:5, 449-466

To link to this article: http:// dx.doi.org/ 10.1080/ 01634372.2010.487886

\section{PLEASE SCROLL DOWN FOR ARTICLE}

Full terms and conditions of use: http://www.tandfonline.com/page/terms-and-conditions

This article may be used for research, teaching, and private study purposes. Any substantial or systematic reproduction, redistribution, reselling, loan, sub-licensing, systematic supply, or distribution in any form to anyone is expressly forbidden.

The publisher does not give any warranty express or implied or make any representation that the contents will be complete or accurate or up to date. The accuracy of any instructions, formulae, and drug doses should be independently verified with primary sources. The publisher shall not be liable for any loss, actions, claims, proceedings, demand, or costs or damages whatsoever or howsoever caused arising directly or indirectly in connection with or arising out of the use of this material. 


\title{
Developing Brokered Community Transportation for Seniors and People With Disabilities
}

\author{
JERRY MARX, CHRISTIE DAVIS, CAITLIN MIFTARI, \\ ANNE SALAMONE, and WENDY WEISE \\ Department of Social Work, University of New Hampshire, Durham, New Hampshire, USA
}

\begin{abstract}
Communities are exploring ways to increase transportation coordination to improve access for seniors. One such effort is a brokered transportation system in which one agency serves as the central point of contact for ride information or actually arranging transportation for clients of multiple programs by use of a combination of transportation services. A team of social work faculty and students from the University of New Hampshire (UNH) Social Work Outreach Center, a center that provides service learning opportunities to students, collaborated with a local coalition to investigate the specific transportation needs of the region's senior citizens. A total of 641 people participated in the survey. Results indicate that the study population experiences problems reliably meeting daily living needs due to inconsistent or unavailable private and public transportation options. Study findings also indicate the promising potential of brokered transportation systems, particularly for isolated seniors in rural and suburban areas with relatively limited public and private transportation options.
\end{abstract}

KEYWORDS Ageism, transportation, mixed methods

Beginning with the creep and crawl of infancy through the halting, unsteady gait of old age, the ability to get around defines and shapes one's world. One's relationships with friends and family, engagement in one's community, and one's very self-concept are affected by one's mobility (Finn \&

Received February 19, 2010; accepted 19 April 2010.

Address correspondence to Jerry Marx, PhD, MSW, Department of Social Work, University of New Hampshire, Pettee Hall, Durham, NH 03824, USA. E-mail: Jerry.Marx@unh.edu 
Sterns, 2003). Both the 5-year-old in time out and the inmate sentenced to a prison term understand restriction of mobility as the quintessential form of punishment (Freund, 2003).

In modern society, transportation is fundamental to one's ability to be mobile. For most people, the ability to get to work or school, to connect with friends and family, to shop for the essentials of daily living, to seek medical attention and access social services, and to recreate is dependent on some form of transportation. During the last half of the 20th century, the automobile undeniably became the primary means for most Americans to get from one place to another (Finn \& Sterns, 2003). However, for many seniors and people with disabilities, the use of an automobile is not an option, and they must rely upon public transportation. Nevertheless, public transportation often presents challenges for these specific populations.

\section{PROBLEM DESCRIPTION}

Data from the National Housebold Transportation Survey of 2001 (as cited in Bailey, 2004) found that 21\% of Americans aged 65 years and older do not drive for a variety of reasons. Declines in health, eyesight, and physical or mental abilities are cited, as well as safety concerns, lack of access to an automobile, or personal preference. Among those aged 65 years and older, close to half (49\%) or about 3.6 million stay home on any given day because they lack transportation options. Older nondrivers make 15\% fewer trips to see a doctor; 59\% fewer shopping trips and visits to restaurants; and 65\% fewer trips for social, family, and religious activities.

For individuals with disabilities, the 2002 National Transportation Availability and Use Survey (US Department of Transportation, Bureau of Transportation Statistics, 2003) found, that regardless of disability status, people with disabilities used personal automobiles for local transportation more than any other mode of transportation. However, $12 \%$ of people with disabilities have problems getting the transportation they need. This survey found that among respondents, 26\% reported lack of having a car as the problem, whereas $17 \%$ reported that their disability makes transportation difficult to use, and 33\% reported that public transportation was limited or nonexistent in their particular area. Other problems with transportation reported by people with disabilities included: "buses don't run on time" (13\%), "buses don't run when needed" (8\%), and "bus stops are too far away" (8\%). This survey also found that 528,000 people with disabilities never leave home because they experience transportation difficulties.

Although today's seniors are enjoying better general health than in the past, longer life expectancies will cause an increase in the number of seniors with disabilities (United States Department of Health and Human Resources 
[USDHHR], Administration on Aging [AOA], 2005). And, as such, dependency on transportation assistance among older individuals is growing (American Public Transportation Association [APTA], n.d). Some government agencies do provide transportation assistance for seniors and people with disabilities. For example, the USDHHS provides grants for supportive services and senior centers providing transportation services to elders, as well as requiring states to assure transportation for medical services to Medicaid eligible persons. The US Department of Transportation provides financial assistance to nonprofit organizations that meet the transportation needs of elderly persons and persons with disabilities where public transportation services are inappropriate, insufficient, or unavailable. However, inconsistency in coordination of these services continues to leave many elders and people with disabilities "transportation disadvantaged" (United States General Accounting Office, [GAO], 2003, p. 2). This disadvantage significantly impacts quality of life and independence issues for these populations.

Clearly, access to transportation is a significant problem for many within these growing minority populations (GAO, 2003). The Baby Boom Generation will begin turning 65 in 2011 (Federal Interagency Forum on Aging-Related Statistics, 2008), and the fastest growing demographic group is people 85 years of age and older (USDHHR, AOA, 2005). With age also come declines in abilities that impact mobility.

As a result of the Transportation Equity Act for the 21st Century, first authorized in 1998 and reauthorized in 2005, federal, state, and local entities are exploring ways to improve transportation coordination to improve access for seniors and people with disabilities by integrating public transportation with community-based and human-service transportation services (APTA, nd; USDHHR, AOA, 2005; GAO, 2003, 2004). In their exploration of coordination efforts, the GAO (2003) noted three examples of coordination efforts undertaken by states: coordinated planning, shared use of vehicles among multiple programs, and brokerages.

In coordinated planning, "some combination of human service and transportation agencies and providers work together to plan transportation services for their clients" (GAO, 2003, p. 18). Coordination by "shared use of vehicles among multiple programs" is vehicles owned by one program being used by multiple programs (GAO, 2003, p. 19). And a brokerage is a type of coordination where one agency serves as the central point of contact for providing ride information or arranging transportation for clients of multiple programs. These three examples of coordination are not mutually exclusive, however, because one entity might feature all three. Consequently, it is difficult to compare and evaluate one approach with another. The GAO (2003) did conclude that such coordination efforts, in general, have produced improved customer service in that coordination can minimize confusing duplication and fragmentation of services. In addition, coordination can reduce the cost per service trip-in some cases by $20 \%$. 


\section{REVIEW OF PAST RESEARCH}

Transportation in New Hampshire

The Alliance for Community Transportation (ACT) is a coalition of more than 20 health and human service agencies, municipalities, transit providers, and consumers whose mission includes coming together to increase access to transportation through improving coordination of present transportation resources in Strafford and Eastern Rockingham Counties of the Seacoast region of New Hampshire (The Center for Health, Energy \& the Environment, 2007). As in the rest of the nation, New Hampshire is recognizing demographic trends requiring an examination of the state's public transportation needs. Results from a 2005 statewide survey of residents 18 and older (Institute on Disability/UCED at the University of New Hampshire, and Community Action Program of Belknap-Merrimack Counties, Inc., 2005) indicated that only 34 of New Hampshire's 259 towns have access to fixedroute transportation, and one in four respondents did not know if public transportation was available. Survey results indicated about $4.5 \%$ and $8 \%$ (45,000-80,000 out of an estimated 1 million New Hampshire residents aged 18 and over) of New Hampshire adult residents had missed or chosen not to schedule a medical appointment because of unreliable transportation, and an estimated .4\%-1.9\% (4,000-19,000 adults) missed four or more medical appointments in the past year because they did not have transportation. And finally, the survey estimated that approximately $9.5 \%$ or $95,000 \mathrm{New}$ Hampshire adult residents would no longer be able to drive themselves in the next few years.

\section{Transportation in the New Hampshire Seacoast Region}

In the Seacoast region, current census data indicates that the Seacoast's seven largest municipalities are home to approximately 60\% of the region's individuals aged 65 and older (The Center for Health, Energy \& the Environment, 2007). This population must deal with such transportation issues as a condition or disability that prevents, driving as well as inconsistent access to a reliable automobile (Schlachman, 2007). Human services agencies in the Seacoast area are providing transportation to their elderly clients. These providers utilize a total of approximately 52 vehicles ranging from automobiles to large buses. Thirty-nine of these vehicles are equipped with wheelchair access. About one-third of these available vehicles are fixedroute buses operated by COAST-The Cooperative Alliance for Seacoast Transportation. However, existing human services transportation providers may only be reaching about one-quarter of elderly persons who are transportation-disadvantaged, or transit-dependent, in the Seacoast region. Many of these individuals live in rural areas, or in areas without fixed-route bus service. In addition, smaller towns within the region are less likely to 
have human service agencies that provide transportation (The Center for Health, Energy \& the Environment, 2007).

\section{Best Practices}

Given limited resources and increasing requirements for demonstrated effectiveness, only those program efforts that can demonstrate cost effectiveness may attract funding and remain viable. One such effort, as noted earlier, is a "brokered transportation system" in which one agency or provider serves as "the central point of contact for providing ride and eligibility information or actually arranging transportation for clients of multiple programs by use of a combination of transportation services" (GAO, 2003, p. 18). Transportation brokerages, which vary in form from state to state, have demonstrated an ability to provide quality, efficient, and cost effective transportation for populations that are identified as transportation disadvantaged. For example, brokerages in such diverse states as Colorado, Washington, New York, Oklahoma, and Oregon have shown success in these areas. To illustrate, Arapahoe County in Colorado set up a transportation brokerage in the early 1980s that coordinates medical, as well as senior, transportation throughout the county and three additional counties. Utilizing 19 service providers, the County authorizes payments of mileage claims, distributes bus passes and tokens, and assigns Medicaid trips. (The County bills the state of Oregon on a fee-for-service basis). The cost per trip for this brokerage system is $\$ 10.20$ compared to the state average of $\$ 24$. In contrast, the state Medicaid agency in Washington state contracts with several public and private nonprofit agencies, including Councils on Aging, to serve as regional brokers of transportation for the whole state. As an indicator of its effectiveness, the number of medical trips in Washington grew from 485,000 in 1990 to 2 million in 2000 (Summer, Friedland, Mack, \& Mathieu, 2004, pp. 18, 20). As a further illustration, three communities in New York joined to form a brokered transportation system and saved an estimated \$92,000 in 2001 (GAO, 2003). Based on previous experience in other states, a brokered system may also prove to be a quality, efficient, and cost effective method for providing transportation to senior citizens in the Seacoast New Hampshire region.

\section{RESEARCH OBJECTIVES}

The previously-described ACT coalition has a vision of implementing a transportation brokerage system that will improve coordination of the existing demand-response transportation resources that serve transportationdisadvantaged seniors in the Seacoast Region. A team of faculty and graduate students from the Social Work Department of the University of New 
Hampshire (UHN) collaborated with the ACT coalition with the objective to investigate the specific needs of the region's senior citizens age 60 and over. The research was conducted through the UNH Social Work Outreach Center in Dover, NH. The Center provides service learning opportunities to UNH undergraduate and graduate social work students. This study, an example of such service learning, explored the transportation systems currently available to the study population, and the degree to which the study population was aware of these systems. In addition, barriers to utilizing currently available systems were identified, and a review of best practices for a brokered transportation system was conducted.

More precisely, this study examined the following research questions pertaining to the study population in Strafford and Eastern Rockingham Counties, New Hampshire: (a) What is the extent to which current transportation services are being utilized in this region? (b) What are the transportation needs in this region? (c) What are the barriers to transportation in this region? (d) What are the transportation preferences of a brokered transportation system in this region? And, (e) in what ways can a brokered transportation system be designed to overcome the current public transportation barriers in this region?

\section{METHODS}

\section{Sample}

This study employed a convenience sample of adults aged 60 and older, considered to be seniors (as well as adults with disabilities who are also serviced by ACT member agencies), living in Strafford and Eastern Rockingham Counties located in the New Hampshire Seacoast region. Eastern Rockingham County encompasses 23 communities, and Strafford County is comprised of 13 communities, and both counties have a mix of urban, suburban, and rural communities. Together, these communities comprise the Seacoast region of New Hampshire. The study focused only on these communities in this region because these are the communities serviced by the ACT coalition member agencies (The Center for Health, Energy \& the Environment, 2007).

\section{Data Collection Procedure}

Faculty and graduate social work students worked closely together to design and distribute a questionnaire, and later analyze the collected information. A total of 3,000 surveys were distributed during the study. Twenty-five hundred surveys were distributed to ACT member agencies. Participants were recruited by agency staff to take the survey while on site at one of the following agencies that provide services to senior citizens: Strafford 
Network, Community Partners, Portsmouth Senior Center, Service Link, Avis Goodwin, Lamprey, and Rockingham County Community Resource Network. Participants had the option to take the survey with staff assistance, and then return it by postage-paid US mail once complete, or they could take the survey home and return it by postage-paid mail once complete. An additional 500 participants received the survey through the mail as a result of being on a newsletter mailing list for senior citizens; these surveys were also returned via postage-paid mail.

The survey was a 32-question, self-administered, pencil-and-paper questionnaire consisting of closed-ended, open-ended, and Likert-scale questions. The survey was pretested by ACT members including consumers, and agency and transportation administrators. The survey was designed to meet the needs of individuals with low vision ability. Survey responses were confidential, and participants had the opportunity to elect to be entered into a drawing for a \$50 gift certificate to a local grocery store. Drawing entries were removed from survey prior to data being entered for analysis. A total of 641 out of 3,000 surveys were returned, yielding a response rate of $21.4 \%$.

\section{Data Analysis Strategy}

Data analyses were conducted using SPSS for Windows, a quantitative analysis and management program. Descriptive statistics were analyzed to answer the research questions. In addition, qualitative data were compiled using standardized open-ended questionnaire items and examined for relevant themes.

\section{FINDINGS}

\section{Characteristics of Survey Respondents}

Women comprised the bulk of survey respondents $(78.3 \% ; n=476)$, with men making up 21.5\% $(n=131)$, and a transgendered individual rounded off the remaining $.2 \%(n=1)$. The majority of respondents, $73.7 \%(n=$ $465)$ reported their age as 60 years or older, and 30.8\% $(n=195)$ of these seniors are 80 years of age and older; $26.3 \%(n=166)$ reported their age as between 18 and 59 years. Although 60.2\% $(n=379)$ of the respondents identified themselves as retired, 8.6\% $(n=54)$ reported being currently employed. Nearly one-third, 31.3\% $(n=197)$ indicated that they do not work for a variety of reasons, and 5.4\% $(n=34)$ were currently looking for employment. Forty-two percent (42\%; $n=265)$ reported living alone, $23 \%(n=145)$ live with a spouse or partner, $15.6 \%(n=100)$ live with family or friends, nearly 1 in 5 (19.3\%; $n=121)$ live in senior housing, an assisted living facility or other living arrangement, and the overwhelming majority of respondents $(95.5 \% ; n=556)$ reported living within 10 miles 
of their town center. Slightly more than two-thirds of respondents, $67.5 \%$ $(n=396)$, reported annual incomes of $\$ 19,999$ or less, yet $21.6 \%(n=127)$ reported annual incomes of between $\$ 20,000$ and $\$ 39,999$, and $10.7 \%(n=$ 63) had annual incomes of $\$ 40,000$ or more. The majority of respondents, $86.3 \%(n=535)$, identified themselves as Caucasian, and $13.7 \%(n=85)$ identified as belonging to a minority.

\section{Current Transportation Usage and Need}

Research question \#1: What is the extent to which current transportation services are being used by the study population?. The ACT Transportation Survey found that respondents use a variety of modes of transportation to get from place to place. Table 1 illustrates the methods of transportation used by survey respondents. It is noted that nearly half of respondents $(51.6 \%$; $n=320)$ drive themselves, close to two-thirds $(64 \% ; n=397)$ reported that family and friends provide transportation for them, $26.6 \%(n=165)$ reported that they walk to get to places and activities, and nearly 1 in 5 $(19.5 \% ; n=121)$ rely on agency buses and vans, and $14 \%(n=87)$ use the public bus.

Relationships were explored between current modes of transportation and willingness to use a brokered transportation service. Significant relationships were found for those who reported currently using an agency bus or van for transportation $\left(\chi^{2}=29.743, \mathrm{df}=3, p=.000\right)$, for those reporting relying on family or friends for transportation $\left(\chi^{2}=15.852\right.$, $\mathrm{df}=3, p=$ $.001)$ as well as for those who are able to drive themselves $\left(\chi^{2}=31.862\right.$, $\mathrm{df}=3, p=.000)$.

Research question \#2: What are the transportation needs of the study population?. After briefly describing what a brokered transportation service was, participants were asked several questions about their transportation needs. Close to $80 \%$ of survey respondents $(78.3 \% ; n=485)$ reported that they probably or definitely would use a brokered transportation system if it

TABLE 1 Current Transportation Usage $(N=620)$

\begin{tabular}{lrr}
\hline Mode of transportation & $n$ & $\%$ \\
\hline Drive self & 320 & 51.6 \\
Get rides from family/friends & 397 & 64.0 \\
Public bus & 87 & 14.0 \\
Agency bus/van & 121 & 19.5 \\
Taxi & 69 & 11.1 \\
Wheelchair & 33 & 5.3 \\
Walk & 165 & 26.6 \\
\hline
\end{tabular}

Note. Percentages do not sum to 100 because respondents had the opportunity to choose all that apply. 
were available. When asked how often they would use the service, 39.5\% $(n=244)$ of respondents reported that they did not currently know, and only $8.9 \%$ ( $n=55)$ reported that they would not use the service. Yet, onethird of respondents ( $n=204$ ) estimated that they would likely use the service 2 or 3 days a week. Table 2 indicates the majority of respondents, $77.6 \%$ ( $n=477)$, would use a brokered transportation service to get to healthcare appointments, yet 63.9\% $(n=393)$ would use it to go grocery shopping, and 51.5\% ( $n=317)$ would do errands using a brokered transportation service. This comment by one respondent sums up a major theme in the qualitative findings: "If I could get dependable transportation, it would make some very difficult circumstances much, much easier."

Pearson's Chi-Square analyses indicate significant relationships between previous inabilities to get to specific locations or activities in the past 12-months, and where a brokered transportation service would likely be used. A significant relationship was found between previous inability to get to work or school and likelihood of using a brokered transportation service to get to a job $\left(\chi^{2}=60.898, d f=1, p=.000\right)$. Similarly, a significant relationship was found between previous inability to get to work or school and likelihood of using a brokered transportation service to get to school or vocational training $\left(\chi^{2}=64.760, d f=1, p=.000\right)$. In addition, significant relationships were found between previous inability to run errands and likelihood of using a brokered transportation service to go grocery shopping $\left(\chi^{2}=12.392, d f=1, p=.000\right)$, as well as previous inability to get to healthcare appointments and likelihood of using a brokered transportation service to go to healthcare appointments $\left(\chi^{2}=38.505, d f=1, p=.000\right)$. Thus, respondents seem to view a brokered transportation system as a solution to various personal transportation problems.

Although the majority $(71.3 \% ; n=442)$ of respondents indicated that they do not need physical assistance or special equipment when going out, $17.7 \%$ ( $n=110)$ do need assistance getting in or out of a car or van,

TABLE 2 Where Would you Travel Using a Brokered Transportation Service? $(N=615)$

\begin{tabular}{lcc}
\hline & $n$ & $\%$ \\
\hline Healthcare appointments & 477 & 77.6 \\
Grocery shopping & 393 & 63.9 \\
Errands (excluding grocery shopping) & 317 & 51.5 \\
Recreational/social activities & 219 & 35.6 \\
Place of worship & 125 & 20.3 \\
Volunteer activities & 95 & 15.4 \\
My job & 48 & 7.8 \\
School/vocational training & 34 & 5.5 \\
\hline
\end{tabular}

Note. Percentages do not sum to 100 because respondents had the opportunity to choose all that apply. 
and $15.5 \%(n=96)$ require assistance getting on or off of a public bus. Furthermore, 34.3\% $(n=210)$ use a walker or cane, and $1.7 \%(n=11)$ use crutches. Finally, $8.7 \%(n=53)$ of respondents use a wheelchair when going out, a guide dog or service animal is used by $.8 \%(n=5)$ of survey respondents, and $7.6 \%(n=47)$ need some kind of assistance getting in or out of their home.

Transportation barriers/Research question \#3: What are the transportation barriers of the study population?. Although the majority of respondents $(61 \% ; n=622)$ report that they are currently licensed to drive, and $85 \%$ ( $n$ $=393$ ) of those who are licensed report they have a vehicle readily available to them, only $51.6 \%(n=320)$ report that they drive themselves to the places and activities they need. Survey respondents indicated that unreliable transportation prevented them from participating in important activities. For example, $35 \%(n=212)$ of the sample reported that they were unable to participate in recreational or social activities due to unreliable transportation, and $44.4 \%(n=272)$ reported being unable to run errands (i.e., going to the bank, grocery store, or pharmacy). Table 3 illustrates the number of times in a 12-month period that unreliable transportation has prevented respondents

TABLE 3 Number of Times in the Past 12 Months Unreliable Transportation Prevented Respondents From Various Activities

\begin{tabular}{lrr}
\hline Activity & $n$ & $\%$ \\
\hline Work/school $(N=600)$ & & \\
1 to 4 times & 51 & 8.5 \\
5 to 9 times & 18 & 3.0 \\
10 or more times & 28 & 4.7 \\
Does not apply to me & 345 & 57.5 \\
Never, I have transportation & 158 & 26.3 \\
Health care appointments $(N=610)$ & & \\
1 to 4 times & 164 & 26.9 \\
5 to 9 times & 39 & 6.4 \\
10 or more times & 28 & 4.6 \\
Does not apply to me & 38 & 6.2 \\
Never, I have transportation & 341 & 55.9 \\
Social/recreational activities $(N=605)$ & & \\
1 to 4 times & 105 & 17.4 \\
5 to 9 times & 43 & 7.1 \\
10 or more times & 64 & 10.6 \\
Does not apply to me & 138 & 22.8 \\
Never, I have transportation & 255 & 42.1 \\
Run errands $(N=612)$ & & 6.7 \\
1 to 4 times & 120 & 48.9 \\
5 to 9 times & 59 & 93 \\
10 or more times & 93 & 19.6 \\
Does not apply to me & 299 & \\
Never, I have transportation & & \\
\hline
\end{tabular}

Note. Percentages do not sum to 100 because respondents had the opportunity to choose all that apply. 
from going to such places as work or school, health care appointments, social or recreational activities, and errands. As noted, slightly more than one-quarter of respondents $(26.9 \% ; n=164)$ missed 1 to 4 health care appointments in a 12-month period. In addition, nearly 1 in 5 (19.6\%; $n=$ 120) were unable to go to the bank, do grocery shopping, or pick up medications at the pharmacy, for example, at least once and as many as 4 times in a 12-month period; $15.2 \%(n=93)$ were unable to do these errands 10 or more times in a 12-month period. Qualitative data indicate that transportation barriers have a great impact on people's lives. As one respondent noted, "There is no way to get food, medicine, and other necessities without a ride. Wonderful to learn you're out there and investigating this basic need-we do need help!"

The Pearson's Chi-Square analysis (Table 4) revealed a significant relationship between not having a driver's license and inability to go to healthcare appointments $\left(\chi^{2}=38.037, d f=1, p=.000\right)$, participate in social/recreational activities $\left(\chi^{2}=51.422, d f=1, p=.000\right)$, and run errands $\left(\chi^{2}=54.886, d f=1, p=.000\right)$.

In addition to the unreliability of transportation, respondents also indicated that weather and driving conditions, as well as having a disability, kept them from driving at times. Snow was a reason not to drive for a majority of respondents (53.1\%; $n=207), 47.2 \%(n=184)$ reported not driving at night, and close to 1 in $5(19.7 \% ; n=77)$ reported that they do not drive during peak driving times. Nearly 18\% (17.9\%; $n=70)$ of respondents reported that they do not drive because they have a disability. Qualitative data also revealed that the effects of medications or a medical condition prevented respondents from driving at times. In addition, the inability to afford gas and car repairs, as well as vehicle inspection and registration were also noted as prohibitive factors. One respondent summarized it thusly, "I get

TABLE 4 Not Licensed to Drive and Missed Activity

\begin{tabular}{|c|c|c|c|c|}
\hline Missed activity & $\begin{array}{c}\text { Do not have driver's license } \\
\text { (\% of respondents) }\end{array}$ & df & $p$ & $\chi^{2}$ \\
\hline Work/school & & 1 & .026 & 4.949 \\
\hline Yes & $45.7 \%$ & & & \\
\hline No & $33.7 \%$ & & & \\
\hline Healthcare appointments & & 1 & .000 & $38.037^{*}$ \\
\hline Yes & $52.3 \%$ & & & \\
\hline No & $26.7 \%$ & & & \\
\hline Social/recreational & & 1 & .000 & $51.422^{*}$ \\
\hline Yes & $54.8 \%$ & & & \\
\hline No & $25.2 \%$ & & & \\
\hline Errands & & 1 & .000 & $54.886^{*}$ \\
\hline Yes & $52.4 \%$ & & & \\
\hline No & $23.1 \%$ & & & \\
\hline
\end{tabular}

${ }^{*} p<.001$. 
social security disability it's hard to come up with gas money or money to fix my car if something goes wrong. . . . Sometimes I just need someone to help me. . . . It depends on my pain level and amount of pain meds if pain is severe."

Pearson's Chi-Square analyses revealed relationships between a respondent's age and circumstances under which they did not drive (Table 5). A significant relationship was found between age and not driving at night $\left(\chi^{2}=20.251, d f=1, p=.000\right)$, age and not driving during peak drive times $\left(\chi^{2}=6.930, d f=1, p=.008\right)$, as well as age and not driving in snow $\left(\chi^{2}=14.454, d f=1, p=.000\right)$. A separate chi-square analysis also revealed a significant relationship between advancing age and concern about losing ability to drive within the next 5 years $\left(\chi^{2}=20.301, d f=1\right.$, $p=.000)$. Half of survey respondents who currently drive $(50.8 \% ; n=195)$ indicated that they are concerned about losing this ability within the next 5 years, and $56.2 \%(n=172)$ of participants 60 years of age and older report that they are concerned about losing their ability to drive within the next 5 years.

Survey results also found a relationship between living arrangements and inability to travel. Those living alone were, on average, twice as likely to not be able to get to work or school, healthcare appointments, social or recreational activities, and errands than those living with family or friends, or a spouse or partner. These relationships, however, were not statistically significant.

TABLE 5 Age and Circumstance Under Which Respondents Do Not Drive

\begin{tabular}{|c|c|c|c|c|c|}
\hline Circumstances & $\begin{array}{c}18-59 \\
\text { years old }\end{array}$ & $\begin{array}{c}60-95+ \\
\text { years old }\end{array}$ & df & $p$ & $\chi^{2}$ \\
\hline At night & & & 1 & .000 & $20.251^{* *}$ \\
\hline Yes & $22.9 \%$ & $52.5 \%$ & & & \\
\hline No & $77.1 \%$ & $47.5 \%$ & & & \\
\hline On the highway & & & 1 & .178 & 1.814 \\
\hline Yes & $5.7 \%$ & $11.1 \%$ & & & \\
\hline No & $93.4 \%$ & $88.9 \%$ & & & \\
\hline During peak driving times & & & 1 & .008 & $6.930^{*}$ \\
\hline Yes & $8.6 \%$ & $22.5 \%$ & & & \\
\hline No & $91.4 \%$ & $77.5 \%$ & & & \\
\hline Have a disability & & & 1 & .091 & 2.861 \\
\hline Yes & $24.3 \%$ & $15.8 \%$ & & & \\
\hline No & $75.7 \%$ & $84.2 \%$ & & & \\
\hline Raining & & & 1 & .087 & 2.933 \\
\hline Yes & $5.7 \%$ & $13.0 \%$ & & & \\
\hline No & $94.3 \%$ & $87.0 \%$ & & & \\
\hline Snowing & & & 1 & .000 & $14.454^{* *}$ \\
\hline Yes & $32.9 \%$ & $57.9 \%$ & & & \\
\hline No & $67.1 \% \%$ & $42.1 \%$ & & & \\
\hline
\end{tabular}

${ }^{*} p<.01 .{ }^{* *} p<.001$. 


\section{Transportation Preferences and System Design}

Research question \#4: What are the transportation preferences of the study population who would be using a brokered service?. Although findings from this survey indicated that respondents would probably use a brokered transportation service (Likert scale: $1=$ never will, $4=$ definitely will; $M=$ 3.06), qualitative data indicate that respondents want a brokered transportation system that is flexible and reliable, has expanded hours and routes, and is reasonably priced. They want vehicles that are well maintained and inspected with drivers that are trained, knowledgeable, and friendly. And finally, respondents want a brokered transportation system that does not require them to wait long for their ride.

Respondents' had many concerns about using a brokered transportation (see Table 6). Most notably, respondents are concerned with being able to travel when they need $(58.6 \% ; n=356)$, to the location they need ( $49.8 \%$; $n=303)$, and how much it will cost $(46.5 \% ; n=277)$. When asked about vehicles, survey participants indicated a preference for riding in a car $(57.8 \%$; $n=359)$, a van (49.8\%; $n=309)$, or a bus $(35.7 \% ; n=222$ ). And, nearly one-third of respondents (31.4\%; $n=196)$ indicated a willingness to pay up to $\$ 3$ per trip; $29.4 \%(n=184)$ did not know what they would pay for the service, and $17.8 \%(n=111)$ indicated that they are unable to pay (Table 7).

When respondents were asked how important it is for them to know the agency staff/volunteer driver of the vehicle providing transportation, approximately $73.5 \%(n=452)$ indicated that it is somewhat important to extremely important, whereas $26.3 \%(n=162)$ indicated that it is not at all important to know the driver if riding in the driver's personal car. In terms of knowing the staff/volunteer driver when riding in and agency van, 64.8\%

TABLE 6 Concerns Regarding Using a Brokered Transportation Service $(N=608)$

\begin{tabular}{lrr}
\hline & $n$ & $\%$ \\
\hline Unsure of being picked up & 226 & 37.3 \\
Takes too long & 121 & 19.9 \\
Getting back/home & 231 & 38.0 \\
Safety & 162 & 26.6 \\
Will it take me where I need to go & 303 & 49.8 \\
Will it take me when I need to go & 356 & 58.6 \\
Need advance planning & 200 & 32.9 \\
Unknown driver & 114 & 18.8 \\
Uncomfortable sharing a ride & 39 & 6.4 \\
Unknown cost & 277 & 46.5 \\
None & 88 & 14.4 \\
\hline
\end{tabular}

Note. Percentages do not sum to 100 because respondents had the opportunity to choose all the apply. 
TABLE 7 Preferred Cost of Brokered Transportation Service $(N=625)$

\begin{tabular}{lrr}
\hline Cost & $n$ & $\%$ \\
\hline Up to \$3/per trip & 196 & 31.4 \\
$\$ 4-\$ 7 /$ per trip & 106 & 17.0 \\
$\$ 8-\$ 11 /$ per trip & 14 & 2.2 \\
$\$ 12-\$ 15 /$ per trip & 6 & 1.0 \\
$\$ 16-\$ 19 /$ per trip & 1 & .2 \\
$\$ 20+$ /per trip & 4 & .6 \\
I don't know & 184 & 29.4 \\
Not willing to pay a fee & 26 & 4.2 \\
Unable to pay a fee & 111 & 17.8 \\
\hline Note. Percentages sum to over $100 \%$ because a small number of respondents \\
chose more than one answer.
\end{tabular}

( $n=402$ ) responded that it is somewhat important to extremely important, and $35.2 \%(n=218)$ indicated that it to be not at all important. And, finally, where the staff/volunteer driver is driving an agency bus, 61\% $(n=376)$ felt it is somewhat important to extremely important, and 39\% $(n=240)$ indicated that it is not at all important that they know the driver.

Research question \#5: In what ways can a brokered transportation system be designed to overcome the current public transportation barriers in Strafford and Eastern Rockingham Counties?. As indicated previously, a qualitative analysis found that it is important for a brokered transportation system to be flexible and reliable, have expanded hours and routes, and be reasonably priced. Vehicles are to be well maintained and inspected, with drivers that are trained, knowledgeable, and friendly. And finally, a brokered transportation system should not require consumers to wait long for their ride.

When respondents were asked how concerns about a brokered transportation service can be addressed, qualitative findings propose that drivers have safety training and criminal background checks. They want drivers who are cautious and willing to help, and drivers who know how to help. Respondents indicated that they would like to see a license posted in the vehicle. One respondent wrote, "Be sure that drivers are capable and reliable with a good reputation in the community."

With regard to the reliability of a brokered transportation service, respondents reported that promptness, accurate scheduling, and good communication (i.e., ability to accurately answer questions) are important. They also suggested being able to confirm travel plans $24-48 \mathrm{hr}$ in advance. As one respondent put it, "Make sure that they will be coming back to get me."

Respondents also had suggestions for how a brokered transportation service might be flexible. One suggested area of flexibility is in pricing. Respondents suggested that group discounts be considered for consumers going to the same location. Another suggested area of flexibility is in 
expanded hours and routes. Respondents would like a service that operates on weekends and holidays (including school holidays), in inclement weather, and to rural areas of New Hampshire, as well as to Boston and other locations in Massachusetts. As one respondent noted, "I am always searching for rides to Boston for surgery and chemo treatments. I am on a fixed income and have to pay my own way on buses and taxis." Respondents also want flexibility in drop-off locations; they want to be dropped off close to their destination. One respondent simply stated, "Basically, I just need a way to get around so I can get groceries and make my appointments."

\section{STUDY LIMITATIONS}

Although 3,000 surveys were distributed to ACT member agencies for this research, 641 were returned, yielding a response rate of $21.4 \%$, which is not sufficient to be generalizable to the population at large. In addition, the use of a nonrandom convenience sample does not make it a representative sample of all members of a population. Further, although statistical significance was found in some cross-tabulations, frequencies were the predominant statistical outcome to be reported.

\section{IMPLICATIONS FOR SOCIAL WORK PRACTICE}

Although this study has limitations, it nevertheless offers valuable information for social agencies across the nation providing transportation to seniors, particularly for providers in rural and suburban areas where public transportation is typically limited and seniors are relatively isolated. Information obtained from survey respondents indicate that they experience problems reliably meeting their daily living needs due to inconsistent or unavailable private and public transportation options. This is no surprise, yet social workers advocating for improved community transportation need to continually present updated information and statistics to policymakers to successfully gain their support.

Social workers need to also document the fact that the problem of inadequate senior transportation is more pervasive than it appears. This study found that even seniors who appear to have transportation worry continuously about its continued availability and reliability, thus negatively impacting their quality of life. Findings of a significant relationship between willingness to use a brokered transportation service and respondent's current modes of transportation, specifically for people who drive themselves or rely upon family or friends for rides, is likely indicative of a concern about losing these relied upon resources. As noted, close to three-quarters of the sample are elders (73.7\%; $n=465)$, and nearly one-third of this 
elder population are octogenarians and nonagenarians. Their concern for losing the ability to drive in the near future is very present and real. For the nearly two-thirds of respondents who depend on family or friends to provide transportation, willingness to use a brokered transportation service supports the suggestion that they are concerned about overburdening this resource, therefore, making access to this transportation resource uncertain in the future. And finally, as suggested by respondent's concerns regarding a proposed brokered transportation service, those who currently use an agency bus or van for transportation may be willing to use a brokered transportation service because, historically, agency provided transportation may not have reliably taken them where they expressly need to go at a time that met their needs, or may not have guaranteed them a return ride home. In any event, these findings indicate that respondents experience unreliable transportation on occasion for a variety of reasons, making it difficult for them to fully participate in the activities of daily living.

Given that respondents who currently drive, as well as those who do not, reported being unable to reliably do such things as get a haircut, buy groceries, make trips to the bank or pharmacy, keep health care appointments, visit family or friends, or go to church socials due to transportation problems, it should be encouraging to social workers that this research found that an overwhelming majority of respondents reported that they expect that they would use a brokered transportation service, if available. In a time of recession and state budget cuts, the literature indicates that brokered transportation systems have the potential to reduce costs, while increasing service quality for seniors. Yet, state policymakers and planners may need evidence that such systems will, indeed, be used by seniors if developed. This study is useful in this respect. Although nearly 4 in 10 survey participants reported that they do not know how often they would utilize the service, and nearly one-third did not know what they would pay, these finding are likely explained by the fact that this is a new concept. Seniors may need to gain trust that this service is an improvement over known transportation options. However, the finding that the majority of respondents expect that they might use the service anywhere from 1 to 7 days a week supports the premise that a change to a new community transportation system such as a brokered system is not prohibitively threatening to seniors, will be consistently utilized, and is, therefore, a good investment for regions of the country with relatively few community transportation resources.

Not only does this study indicate that brokered transportation services may improve community transportation and reduce associated costs, but social workers might also note the potential for improving senior health care, while reducing state health care spending. Like many regions of the United States, the Seacoast region of New Hampshire is a mixture of urban, suburban, and rural areas, and many are without fixed-route bus service. Most 
respondents reported living within 10 miles of their town center; however, smaller towns within the region do not necessarily have doctor's offices, grocery stores, or pharmacies, which are available in the larger municipalities. The majority of respondents in this study would use a brokered transportation service to get to healthcare appointments, or shop at grocery stores where over-the-counter medications and supplies can be obtained. Consequently, brokered transportation should improve access to timely and consistent health care for isolated seniors, allowing them to stay healthier longer.

And finally, for older adults who do work or go to school, including vocational training, the finding of a significant relationship between having previously missed work or school and willingness to use a brokered transportation service suggests that, perhaps, more people would be able to improve their living circumstances through work, education, or training if reliable transportation were available to them. It also indicates that seniors may view a brokered transportation service as a promising solution to personal transportation problems. In rural states such as New Hampshire, where residents are proud of being self-reliant, this interest in and openness to brokered transportation services should not be minimized, but rather, emphasized by social workers seeking to improve senior transportation.

\section{REFERENCES}

American Public Transportation Association. (nd). The benefits of public transportation: mobility for the aging population. Retrieved from http://www.apta.com/ research/info/online/aging.cfm

Bailey, L. (2004). Aging Americans: Stranded without options. Washington, DC: Surface Transportation Policy Project. Retrieved from http://www.transact.org

Federal Interagency Forum on Aging-Related Statistics. (2008). Older Americans 2008: Key indicators of well-being. Washington, DC: U.S. Government Printing Office.

Finn, J., \& Sterns, H. L. (2003). Introduction. Generations, 27(2), 6-7.

Fruend, K. (2003). Mobility and older people. Generations, 27(2), 70-71.

Schlachman, D. (2007). Exeter regional transportation survey. Portsmouth, NH: Greater Piscataqua Community Foundation, New Hampshire Charitable Foundation Grant to Rockingham Nutrition Meals on Wheels Program.

Summer, L., Friedland, R., Mack, K., \& Mathieu, S. (2004). Measuring the years: State aging trends $\&$ indicators. Washington, DC: Georgetown University-Center on an Aging Society, Health Policy Institute.

Transportation Equity Act for the 21st Century. (2005). Retrieved from http://www. fhwa.dot.gov/Tea21/sumevir.htm\#tacaspp

The Center for Health, Energy \& the Environment. (2007, October). Coordinated public transit buman services transportation plan for the seacoast region of New Hampshire. Strafford, NH: Author. 
The Institute on Disability/UCED at UNH and Community Action Program BelknapMerrimack Counties. (2005, December). New Hampshire speaks out: We want public transportation. Summary Report. Durham, NH: Author.

United States Department of Health and Human Resources, Administration on Aging. (2005). Executive summary: Seniors benefit from transportation coordination partnerships-A toolbox. Promising practices from the aging network. Retrieved from http://www.aoa.gov/prof/transportation/media/ TransportationChoicesToolbox/Executive.Summary.pdf

United States Department of Transportation, Bureau of Transportation Statistics. (2003). Freedom to Travel, BTSO3-08. Washington, DC: Author. Retrieved November 3, 2008 from http://www.bts.gov/publications/freedom_to_travel

United States General Accounting Office. (2003). Report to Congressional requests: Transportation-disadvantaged populations, GAO Report GAO-03-697, June 2003. Retrieved from http://www.gao.gov/new.items/d03697.pdf

United States General Accounting Office. (2004). Report to the chairman, special committee on aging, U.S. Senate. Transportation disadvantaged seniors: Efforts to enbance senior mobility could benefit from additional guidance and information. GAO Report GAO-04-971, August, 2004. Retrieved from http://www. gao.gov/new.items/d04971.pdf 